\title{
Desvendando e Desmitificando Através da Análise Bakhtiana o Planejamento Estratégico de uma Empresa Júnior
}

\author{
Rafaella Cristina Campos ${ }^{1}$ \\ Universidade Federal de Lavras e Faculdade Presbiteriana Gammon - FAGAMMON \\ Lilia Paula Andrade ${ }^{2}$ \\ Universidade Federal de Lavras e Faculdade Presbiteriana Gammon - FAGAMMON \\ Marco Antonio Villarta-Neder ${ }^{3}$ \\ Universidade Federal de Lavras
}

\begin{abstract}
RESUMO
Objetiva-se analisar, sob a ótica da estratégia como prática social, as características de linguagem escrita de um planejamento estratégico de uma empresa júnior situada no sul do estado de Minas Gerais, com base na perspectiva Bakhtiniana de análise do discurso. O planejamento estratégico é uma proposta de trabalho a ser executado em detrimento da prática social que é o trabalho realmente executável, fazendo com que nas organizações as vozes dos atores fiquem abafadas, atônicas pela ideologia de participação coletiva, que é disseminada. Acarreta-se um falso contentamento dos atores organizacionais que acreditam de fato que suas opiniões estão contidas no plano, objetivos e metas estabelecidas pela empresa, permitindo a manifestação dos fenômenos de polifonia e hegemonia.
\end{abstract}

Palavras-chave: Planejamento Estratégico; Polifonia; Hegemonia; Bakhtin.

\begin{abstract}
The objective is to analyze, from the perspective of strategy as a social practice, language features writing a strategic plan of a junior company located in the southern state of Minas Gerais, based on Bakhtinian perspective of discourse analysis. Strategic planning is a proposal for work to be performed at the expense of social practice that is actually executable work, making in organizations the voices of actors from getting muffled, atonic ideology of collective participation, which is widespread. Brings up a false contentment of organizational actors who believe in fact that their views are contained in the plan, objectives and targets set by the company, allowing the expression of polyphony and hegemony phenomena.
\end{abstract}

Keywords: Strategic Planning; Polyphony; Hegemony; Bakhtin.

\section{RESUMEN}

Se pretende analizar, bajo la óptica de la estrategia como práctica social, las características de lenguaje escrito de una planificación estratégica de una empresa júnior situada en el sur del estado de Minas Gerais, con base en la perspectiva Bakhtiniana de análisis del discurso. La planificación estratégica es una propuesta de trabajo a ser ejecutado en detrimento de la práctica social que es el trabajo realmente ejecutable, haciendo que en las organizaciones las voces de los actores queden sofocadas, atónicas por la ideología de participación colectiva, que es diseminada. Se aclara un falso contentamiento de los actores organizacionales que creen de hecho que sus opiniones están contenidas en el plan, objetivos y metas establecidas por la empresa, permitiendo la manifestación de los fenómenos de polifonía y hegemonía.

Palabras clave: Planificación Estratégica; la polifonía; la hegemonía; Bakhtin.

\footnotetext{
${ }^{1}$ Doutoranda em Administração pela UFLA e professora efetiva da Faculdade Presbiteriana Gammon - FAGAMMON rafaella_ccampos@hotmail.com

${ }^{2}$ Doutoranda em Administração pela Universidade Federal de Lavras - UFLA. Professora dos cursos de Administração e Sistemas de Informação na Faculdade Presbiteriana Gammon - FAGAMMON - liliapaulandrade@yahoo.com.br

${ }^{3}$ Professor Associado no Departamento de Ciências Humanas na UFLA - Doutor em Letras Unesp-Araraquara (2002). villarta.marco@dch.ufla.br
} 


\section{Introdução}

Ainda existem poucos estudos que consideram os aspectos discursivos da estratégia e suas especificidades nas organizações. O trabalho terá por objeto de estudo um planejamento estratégico de uma empresa júnior localizada em uma universidade federal do sul de Minas Gerais.

Um planejamento estratégico, além de sua concretização em um documento, possui também por alvo ser de fato praticado e internalizado no cotidiano dos colaboradores de modo que todos os atores caminhem em um só sentido na busca por objetivos.

Já a análise de discurso de acordo com Rocha (2005) propõe o entendimento de um plano discursivo que articula linguagem e sociedade, entremeadas pelo contexto ideológico. A análise de discurso pretende consolidar uma alternativa de análise, mesmo que marginal à perspectiva "tradicional". A análise de discurso propõe então, um novo olhar sobre as práticas linguageiras. É esse olhar diferenciado sobre as práticas estratégicas que o trabalho em questão busca analisar. Para tanto será utilizada a abordagem estratégica como prática social e discursiva. Para essa linha de pesquisa, a estratégia não é algo que uma organização possui, mas algo socialmente construído. Assim, as visões objetivistas e racionalistas da estratégia são deixadas de lado, e o foco de estudo recai sobre seus aspectos subjetivistas.

Nesse sentido, o estudo terá como principal referencia a análise de discurso proposta por Bakhtin que é considerado um dos precursores de visões diferenciadas sobre as teorias de discurso (BARROS; 1997). De acordo com esse autor Bakhtin afirma que a especificidade das ciências humanas está no fato de que seu objeto é o texto (discurso). Ou seja, as ciências humanas voltam-se para o homem, mas é o homem como produtor de textos que se apresenta. Assim sendo o homem não é só conhecido através dos textos, mas se constrói enquanto objeto de estudos nos ou por meio dos textos, Bakhtin propõe para a ciência humana um objeto textual específico, pois pontos de vista diferentes sobre o texto constroem textos, e, portanto, objetos também diferentes.

Utilizando como objeto o documento do planejamento estratégico da empresa júnior avaliada, como base de análise e também como instrumento avaliativo, pergunta-se: Quais são as especificidades textuais e discursivas utilizadas no planejamento estratégico por intermédio da análise de discurso proposta por Bakhtin? Assim sendo, por objetivo geral delimitou-se: analisar, sob a ótica da estratégia como prática social, as características de linguagem de um planejamento estratégico de uma empresa júnior situada no sul do estado de Minas Gerais. Os objetivos específicos do trabalho pretendem: a) Identificar quais são as características textuais e discursivas presentes no documento descritivo do planejamento estratégico dessa empresa júnior; b)Verificar quais são as características de polifonia presentes no corpus; c)Averiguar se o planejamento estratégico em questão possui características com predominância de monofonia ou polifonia; d) Avaliar, dentro do planejamento estratégico, quais são os caracteres de hegemonia presentes nas concepções de estratégia da empresa Junior em questão.

O trabalho irá abordar os conceitos de polifonia e hegemonia propostos por Bakhtin a fim de se averiguar as vozes presentes no discurso implícito no plano estratégico avaliado e também atender aos objetivos propostos. Sendo assim há necessidade de se definir tais conceitos. Polifonia de acordo com Barros (1997) é um conceito usado para caracterizar um tipo de texto em que o dialogismo está presente e são percebidas muitas vozes. Trata-se de um efeito de sentido, decorrente de procedimentos discursivos, de discursos por definição e constituição dialógicos. No que se refere ao conceito de discursos hegemônicos, para Antonio Gramsci, (apud ZACCHI, 2006) são aqueles usados para se legitimar uma ideologia dominante e sustentar relações desiguais de poder. Através da linguagem esses discursos geram um senso comum em torno de situações estabelecidas favoráveis à manutenção de um poder dominante e/ou hegemônico. Nesse sentido o trabalho propõe discutir os discursos hegemônicos e de polifonia relativos a um planejamento estratégico de uma empresa do sul de MG. Sabe-se que um planejamento estratégico recebe influência de muitos discursos e metodologias que muitas das vezes não se tornam realidade no contexto das organizações. O estudo em questão é considerado importante por analisar nas estratégias organizacionais, questões até então despercebidas e não consideradas pela maioria dos estudos organizacionais. Martin (1986) reforça essa ideia ao dizer que "ao alterar a definição do que está sendo estudado, altera-se também a forma de ver e 
quando diferentes definições são utilizadas para traçar o mesmo território, os resultados se diferem". Ademais o trabalho irá levantar discussão e contribuir para o aprofundamento teórico e a intensificação da produção intelectual sobre o desenvolvimento do tema estratégia como prática social.

\section{Referencial Teórico}

\subsection{Das Abordagens Clássicas à Abordagem Discursiva da Estratégia}

Para Barry e Elmes (1997): Estratégia como prática discursiva era anteriormente aplicada a outros campos organizacionais. $\mathrm{O}$ autor salienta que existem poucos estudos que descrevem a estratégia narrativa utilizando conceitos formais e modelos. É exemplo de narrativa "toda apresentação simbólica de uma sequência de eventos ligados por assuntos e relacionados pelo tempo". Nesse sentido o planejamento estratégico poderia ser analisado sob a abordagem narrativa, visto que se não deixa de ser um evento sequencial, relacionado pelo tempo e apresentado simbolicamente através de reuniões e documentos.

A narrativa considera as experiências individuais, observando como funcionam como "partes do todo". Trata do estudo das ações humanas, nesse mesmo trabalho ainda é descartada uma semelhança entre narrativa e comunicação nas organizações. A nova abordagem defende que não existe uma verdade testável de "estratégia", mas que esta pode assumir diversas formas, que dependem da história e valores de quem a pratica. Em outras palavras, que uma estratégia, pode ter inúmeras interpretações. Existe a preocupação em como a linguagem é utilizada para construção de significados, assim como em explorar maneiras sobre como os stakeholders criam os discursos. Nessa linha, o autor faz uma crítica às estratégias tradicionais, que ignoram o papel da linguagem no processo de decisão estratégica. Assim como Whittington (1996) e Jarzabowski (2005), Barry e Elmes (1997) acredita que a estratégia está ligada mais à história da organização, e para alcançar o sucesso, ela depende basicamente da "aceitação, aprovação e adoção". Já Barry e Elmes (1997), ao se referir às teorias clássicas sobre estratégia, o autor, afirma que em meio a tantas teorias (MINTZBERG, PORTER, MILIES e SNOW) as pessoas ficaram confusas, em saber qual tipologia poderia ser a certa. O autor sugere que se aumentem estudos sobre "quem" para então propiciar o desenvolvimento das perspectivas futuras de estratégia.

\subsection{Empresas Juniores: Uma Breve Descrição de Procedimentos Internos e Representatividade Social}

De acordo com Oliveira (2003) uma empresa júnior nada mais é que uma organização ligada a uma IES (Instituição de Ensino Superior), gerida por alunos, tanto nos aspectos técnicos de prestação de serviços e projetos, como da gestão da organização. Os trabalhos técnicos são supervisionados por professores; desta forma os alunos não trabalham sozinhos e a finalidade principal é estabelecer uma relação entre teoria e prática do processo de ensino e uma melhor qualificação profissional.

Segundo Moretto Neto et al (2004) os objetivos de uma empresa júnior são: prestar serviços de consultoria às micro, pequenas e médias empresas, ajudando-as a se desenvolver através de informações que busquem solucionar seus problemas internos e externos; dar acesso aos pequenos empresários a um serviço de alto padrão de consultoria a preços acessíveis; estabelecer um contato mais efetivo entre estudantes e o mercado de trabalho visando a integração e ao desenvolvimento das potencialidades existentes, facilitando então o ingresso do aluno ao mercado de trabalho; coletar informações, experiências e identificar novos temas para o estudo e aprofundamento em busca de soluções criativas e inovadoras e promover maior integração entre universidades e organizações, proporcionando vantagens mútuas.

A ideia de Empresa Júnior surgiu na França, em 1967, e teve como objetivo oferecer aos estudantes universitários uma opção para melhor qualificação de sua prática profissional. Criaram então uma 
associação sem fins lucrativos denominada Junior Enterprise. Começou na década de 80 o Movimento Empresa Júnior (MEJ) e, a partir desse momento, as empresas juniores se fortaleceram e se expandiram pelo mundo (Espanha, Itália, Inglaterra, Suíça, dentre outros).

O conceito de empresa júnior chegou ao Brasil em 1987, por iniciativa de João Carlos Chaves. Depois de então o movimento só vem crescendo e ganhando cada vez mais espaço no mercado e nas instituições do país. Atualmente existem no país mais de 600 empresas juniores. Com a finalidade de representar as empresas juniores a nível nacional e desenvolver o movimento empresa Junior como agente de educação empresarial, surgiu a Brasil Júnior (Confederação Brasileira de Empresas Juniores). Este órgão é formado por 11 federações, que representam 10 estados brasileiros e o Distrito Federal. A federação que representa Minas Gerais, nesse contexto, é a FEJEMG (Federação de Empresas Juniores de Minas Gerais).

Esta federação de Minas Gerais foi fundada em 1995, na cidade de Lavras, MG. A FEJEMG é uma associação civil sem fins lucrativos. Possui a finalidade de promover a interação e união das empresas juniores do Estado de Minas Gerais, de modo a incentivar e fortalecer o Movimento Empresa Junior do Estado de Minas Gerais. A FEJEMG conta com 27 empresas federadas de diversos cursos de graduação e cidades de Minas Gerais. De acordo com Silva (2010) as empresas juniores federadas à FEJEMG compartilham conhecimentos, num âmbito de relacionamento entre as empresas, uma vez que a interatividade promovida por elas proporciona um ambiente de cooperação e compartilhamento de competências que levam a formação da rede.

\subsection{Análise de Discurso sob a ótica de Bakhtin}

De acordo com Zacchi (2003), discurso é um termo que tem sido aplicado em diversas disciplinas com as mais variadas definições. Para Jaworski e Coupland, 1999, p. 3, apud Zacchi (2003) "discurso é o uso da linguagem em relação a formações sociais, políticas e culturais", em outras palavras, que a linguagem possui interação direta com a sociedade e seus indivíduos. Ainda de acordo com este autor práticas discursivas podem ser empregadas para se legitimar ideologias dominantes, e também como meio de resistência a elas.

O conceito de hegemonia, que foi introduzido por Antonio Gramsci, pressupõe uma constante reconquista do consentimento da maioria ao sistema subordinante. Entretanto Zacchi (2003) chama a atenção ao fato de que uma ideologia dominante será sempre motivo de resistência a consentimentos de ordem social, sendo por esse motivo instável. Essa visão hegemônica pode expressar interesses daqueles que detêm os meios de dominação.

A hegemonia para Tavares de Jesus (apud ZACCHI, 2003) implica "tanto direção quanto dominação"; dirigir está relacionado ao conceito de guiar, ser líder, e dominar relaciona-se a governar ou ser chefe. A hegemonia seria a união desses dois elementos. Relaciona-se não apenas com a estrutura econômica e organização política da sociedade, mas também com orientações ideológicas e culturais.

Para Bezerra (2010), o discurso é em si uma esfera da hegemonia cultural, pois o conceito de hegemonia implica a constituição de práticas em geral discursivas que naturalizam relações e ideologias particulares.

De acordo Bezerra (2010) na ótica da polifonia, o personagem possui a "autoconsciência", o sujeito passa a ser visto com igual em direito de interagir no diálogo. A característica da polifonia, seria a posição do autor como regente do coro de vozes que participam do processo dialógico, se define pela multiplicidade de vozes e consciências independentes e imiscíveis, sendo essas vozes, de sujeitos de seus próprios discursos. As personagens participam da história, interagem com o autor, não interfere nas vozes e nem as controla; elas participam do diálogo de forma igualitária.

De acordo com Goulart (2001), a noção de polifonia, organiza-se a partir de um centro organizador exterior, que é povoado por muitas visões de mundo, muitas palavras, histórias e várias origens, que dialogicamente se fundam no social. Essa noção é então entendida como um fenômeno social da interação verbal como realidade fundamental constitutiva da linguagem e da consciência dos indivíduos. 
Já o conceito de ideologia, segundo Bakhtin (2006) é um reflexo das estruturas sociais, sendo assim, toda modificação da ideologia encadeia uma modificação da língua. De acordo com Miotello (2010), Bakhtin insere nessa questão de ideologia, outras discussões filosóficas tratadas de forma concreta e dialética. Bakhtin constrói esse conceito em movimento, como a constituição de signos, ou a constituição da subjetividade. A ideologia oficial é entendida como relativamente dominante e procura implantar uma concepção única de produção de mundo. A ideologia de cotidiano é considerada como a que brota e é constituída nos encontros casuais e fortuitos, no lugar dos sistemas de referência, na proximidade social com as condições de produção e reprodução da vida. Segundo esse autor, uma definição de ideologia é dada por um dos autores do círculo de Bakhtin, para Voshinov/Bakhtin, entende-se por ideologia "o conjunto de reflexos e interpretações da realidade social e natural que tem lugar no cérebro do homem e se expressa por meio de palavras [...] ou outras formas signicas".

\section{Metodologia de Pesquisa}

O procedimento previsto para a análise de dados desta pesquisa consiste na análise de discurso do planejamento estratégico, que compreende os anos de 2005 e 2006 de uma empresa júnior universitária do sul do estado de Minas Gerais; mas a avaliação do material está sendo feita num período posterior a sua elaboração e execução (ano de 2012). Análise de discurso é definida de acordo com Bakhtin 2009, como uma prática da linguística e da que tem como objetivo avaliar o 'além textual', ou seja, construções ideológicas presentes no texto, mas não explícitas nele. Bakhtin 2009 tem como proposta na análise de discurso avaliar não somente o texto, mas o que é dito por ele. Tendo em vista que será utilizado um documento escrito delineando o planejamento estratégico de uma empresa júnior universitária do sul do estado de Minas Gerais, este artigo é classificado como um estudo de caso porque, segundo Minayo (2000), se restringe a amostra de um único objeto, unidade individual.

Primeiramente deve-se ressaltar que planejamento estratégico tem variadas definições e entendimentos teórico/práticos, para este trabalho, será utilizada a definição de Mintzberg, Ahlstrand e Lampel (2010) que entendem planejamento estratégico como sendo processo formal de estabelecimento de metas e prazos a serem cumpridos e determinados pela gestão organizacional em detrimento da prática social desta mesma organização. Ou seja, o planejamento estratégico é implantado para alcançar objetivos a curto, médio e longo prazo que gerem benefícios à empresa e organizem a conduta de seus colaboradores em torno de uma tarefa comum.

Cada organização administra a elaboração e implantação do seu quadro estratégico de uma forma específica, levando em conta não só as singularidades de seu polo e sua cultura social externa, mas também, senão principalmente, o modelo matricial mais engajado e compatível com seus objetivos. No caso da empresa júnior que segue neste trabalho, utiliza-se o modelo citado por Laran (2001) que consiste nos seguintes passos:

$1^{\text {a }}$ Etapa: Análise do Ambiente Interno e Externo da Empresa Júnior;

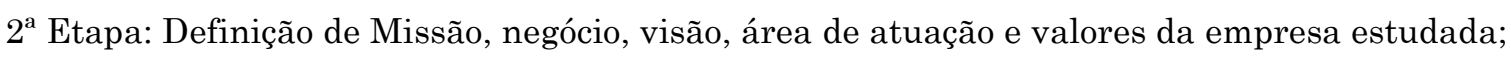

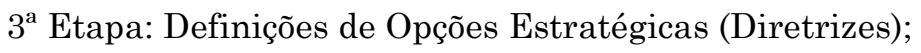

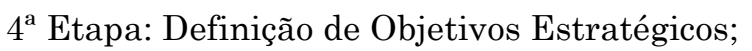

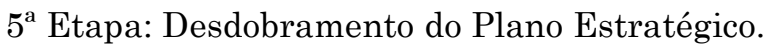

Visto que o modelo de planejamento estratégico da empresa em questão segue estas cinco diretrizes de implantação, o sistema avaliativo deste artigo será fragmentado nestas cinco etapas, visando sempre o objetivo principal do nosso trabalho que é identificar as variáveis presentes de polifonia e hegemonia; propostos por Bakhtin. 
De acordo com Vaara (2010) deve-se ter certo cuidado na avaliação de um documento estratégico, pois, "em sua produção e interpretação pelos atores organizacionais, a estratégia pode sofrer influências políticas e resultar na criação de muitos significados e diversos pontos de vista e ações"; e isso pode trazer, segundo Bezerra (2010) um ruído de informação de passagem de valores da mesma organização que são errôneos e não pertencentes a mesma.

\section{Análise do Corpus}

\subsection{Análise de Discurso sob a ótica de Bakhtin}

O período de auditoria interna, segundo Mintzberg, Ahlstrand e Lampel (2010) é o mais frágil e mais suscetível ao que Bezerra (2010) chamou de polifonia, num múltiplo processo em que se dá simultaneamente significante e significado a um mesmo fenômeno ao pior, a falta dele. Ou seja, se nos referirmos, por exemplo, no processo de avaliação do clima organizacional, (como foi feito na empresa júnior universitária que se trata neste artigo) fazer parte da organização e se colocar como objeto avaliado dela são situação tão dependentes de si que não se excluem, confundindo a função de um com a função de outro.

Pode-se ver que as vozes de enunciatário e enunciador se confundem numa miscigenação constante, os papéis não são definidos. No decorrer do corpus do planejamento estratégico há constante menção à entidade equipe; chamamos de entidade 'equipe' porque não se vê, não se define, se tem a ideia de integração, mas há uma necessidade de se implantar sistema hierárquico (proposta no organograma) o que sugere uma cadência de poder e portanto, de autoridade, e a distonia entre pontos fracos e fortes apontados na fase de auditoria interna, mostra que há marcadores ideológicos inerentes à vontade individual e/ou coletiva uma vez que se prevalece a organização empresarial.

Temos descrito no planejamento estratégico da empresa júnior que um dos seus pontos fortes seria "Reuniões Semanais com a Diretoria", mas em detrimento disto é colocado como ponto fraco, "Ausência de Reuniões", o que nos sugere uma inconsistência no próprio gerenciamento e comunicação de falhas. O mesmo acontece com os itens "Número de Projetos" e "Apresentação de Casos e Projetos" que foram colocados respectivamente em pontos fortes e fracos, sugerindo novamente uma inconsistência em se colocar em posições distintas de observador e observado. Isso pode nos sugerir: quais são as vozes que imperam sobre estes eventos? Estas distonias são coletivas ou colocadas para o coletivo se sentir apreciado, ouvido? Este duplo diálogo (polifonia) sugere que a gerência estrategicamente se coloca à vista coletiva para fazer parte dela, ou talvez passar a sensação para os subalternos de fazerem parte do corpo de tomada de decisões gerenciais?!

De acordo com Bezerra (2010), a polifonia pode causar um ruído intenso entre enunciador e enunciatário, e este evento ocorre claramente e de forma indiscriminada quando o papel de ambos é assumido por apenas um só veículo de comunicação, que neste caso é a gerência estratégica. Para quem se coloca numa situação de observador da situação, logo a princípio vê que até a nomenclatura das variáveis analisadas são contraditórias ao serem colocadas em situações de disparidade como pontos fracos e fortes sendo que epistemologicamente designam a mesma coisa. Por exemplo: Como as reuniões semanais podem ser ao mesmo tempo ponto forte e fraco?

Já quando consideramos a análise do ambiente externo, percebe-se que a presença do que Bezerra (2010) chamou de polifonismo, ou seja, a presença da dialética entre duas ou mais práticas, neste artigo consideramos as práticas organizacionais de duas ou mais empresas, e na empresa júnior universitária, agregam-se ações estratégicas de outras organizações em suas práticas e imprimi suas práticas e outra(s) organização(s), dificultando assim a diferenciação das práticas. Mintzberg, Ahlstrand e Lampel (2010) caracterizam este evento como algo tão intrínseco que a própria micro sociedade que engloba estas organizações e, portanto, estas práticas, não consegue distinguir muitas vezes nem mesmo as próprias organizações.

No planejamento estratégico da empresa júnior, vê-se que como análise de ameaça externa há a captação de uma empresa estudantil similar, mas com público-alvo e prestação de serviços completamente 
diversos, o que a torna uma ameaça é o reconhecimento estudantil, a busca nas aberturas de editais de vaga e o enfoque de apoio que é o mesmo: os professores da instituição. Vê-se também que outra ameaça e outro evento que proporciona a questão do polifonismo o fato de ambas as empresas serem vinculadas a um mesmo departamento da universidade, limitando ainda mais a influência de suas práticas. Da mesma forma que na lista do planejamento estratégico há citado como oportunidade "Parceria com Empresa Estudantil" há também como ameaça "Falta de Apoio de Comprometimento"; o que nos leva a concluir que as práticas organizacionais, apesar de serem intrínsecas, aderem a uma inércia no sentido do movimento de cooperação entre as empresas.

Estes fenômenos nos levam a ressaltar a presença de monologismo, ou seja, as empresas universitárias têm vozes distintas, mas são captadas pelo seu ambiente micro social de forma unitária. Suas práticas se tornam tão similares e sua competitividade interna propulsora de uma fusão que a visão de um receptor externo fica turva e se vê apenas uma voz ecoada, como neste caso. Existe essa monofonia porque não há relações de poder, porque não se percebe a heterogeneidade, nas diferenças não se percebe a hegemonia.

\subsection{Análise da Construção da Missão, Negócio, Visão, Área de Atuação e Valores da Empresa Junior Universitária}

No que se diz respeito à missão da empresa júnior universitária, "Proporcionar melhor capacitação à sua equipe e sucesso aos seus clientes com qualidade e ética", o termo 'equipe' traz uma ideologia diferenciada de trabalho, não se verifica os atores como "proletário" ou mão de obra apenas, tenta-se jogar uma ideologia de trabalho em cooperação, não se traz a ideia de concorrência ou divergência de objetivos. Equipe então pode ter sido utilizada para promover a noção que nessa empresa os atores trabalham de forma harmoniosa em busca de um interesse.

Também como missão dessa organização foi estabelecida "proporcionar sucesso aos clientes com qualidade e ética". Verifica-se nesse discurso uma intenção da empresa em proporcionar sucesso aos clientes, essa fala funcionaria também como um "marketing", pois fica subtendido que seus clientes são empresas que irão ter sucesso, ou serão diferentes positivamente de outras concorrentes. A questão do "sucesso" esse seria um discurso dominante de todas as organizações, este discurso está relacionado, muitas das vezes a ganhos financeiros. Já a menção do termo "qualidade e ética" juntamente com a palavra sucesso, traz a ideia de que seria esse o diferencial que a empresa busca atingir, ou seja, deseja proporcionar o sucesso dos clientes e ao mesmo tempo agir com qualidade e ética. Fica subtendido nessa questão que existem organizações que buscam o sucesso e não se preocupam tanto com o requisito da "qualidade e ética". Existe a ideia nesse conceito também que em alguns casos "sucesso" e "qualidade e ética" seja termos excludentes, e contrapondo a essa exclusão que a empresa Júnior busca a relação e interação desses termos.

A hegemonia predominante no cenário de empresas juniores pode ser analisada no site da Brasil Junior, que seria o órgão direcionador das atividades de todas as empresas juniores. Pode ser analisado no site deste órgão o seguinte discurso:

Uma empresa Junior de acordo com o selo Brasil Junior garante qualidade em seus elementos essenciais de funcionamento, é tida como profissional e ganha mais credibilidade diante dos stakeholders. Isso se a Empresa Junior se comprometer a prestar serviços de qualidade, que geram clientes satisfeitos e fidelização dos mesmos, que podem até indicar novos clientes.

Ao se analisar essa hegemonia de estratégia, determinada pela Brasil Júnior, verifica-se e explicase claramente a grande influencia que essas diretrizes determinadas pela empresa exerceram no discurso da missão "criada" pela Empresa Junior analisada.

Já no item do planejamento estratégico que se refere a negócio, "Administração, Conhecimento e Sucesso Empresarial" percebe-se novamente a presença de uma voz ideológica (sucesso) e aparentemente 
'sem dono', inferindo monofonia e interessantemente interdiscurso simultaneamente. Uma vez que estes critérios descritos no item Negócio são objetivos gerais para qualquer empresa, e por não serem exclusivos de empresa júnior em questão mostram que seu diálogo com as práticas organizacionais de outras empresas infere interdiscurso. Mas também, por ser uma voz sem destinação concreta e também por não parecer vir de um componente concreto da empresa, infere-se o monologismo.

No que se refere à visão, "Ser o diferencial para as empresas na arte administrativa, preservando sempre a responsabilidade na transmissão de conhecimentos através de serviços", o fato de querer ser o diferencial já coloca em cheque toda a prática social da empresa e seu projeto estratégico. Bezerra (2010) e Mintzberg, Ahlstrand e Lampel (2010) corroboram que toda prática organizacional (discursiva), uma vez analisada e tendo tendência ao fenômeno do interdiscurso, dificilmente será diferenciada em suas táticas. Pose ser que a empresa consiga promover o evento a hegemonia, que segundo Bezerra (2010) seria impor sua conduta sobre as demais organizações que são intrínsecas a ela; mas até então este evento não pode ser comprovado nesta empresa júnior, o que também não excluí a tendência ao interdiscurso.

No item valores "Empreendedorismo, Qualidade, Cooperação, Bem-Estar Social, Ética, Profissionalismo", destacamos atenção especial para o item 'cooperação', que delimita o conceito central do planejamento estratégico da empresa júnior universitária. Em contrapartida desta ideologia, surge a polifonia da competitividade estabelecida pelas vozes das intenções de parcerias e 'ameaças', sugeridas pela prefeitura. A todo o momento há forte ligação coma prefeitura com objetivo de se conquistar prêmios, bonificações. Ao mesmo tempo em que o planejamento estratégico tende a um corpus estrutural com ideologia de cooperação, por traz há um dorso de competitividade, marcante de qualquer estrutura hierárquica ascendente e também por qualquer organização empresarial.

\subsection{Análise da Definição das Opções de Estratégia (Diretrizes)}

Neste bloco descreve-se que o foco principal de atendimento de público-alvo da empresa júnior seria a cidade em que está inserida e a microrregião. Isto mostra que o alcance é relativamente pequeno o que nos leva a concluir que as práticas organizacionais terão ainda menos mutação e influência, prevalecendo a miscigenação já feita por meio da hegemonia com a outra empresa universitária local. Pode-se também concluir parcialmente que a hegemonia da empresa por estar isolada na presença de mercado, faz suas práticas serem ainda mais peculiares e ainda menos dispersas.

\subsection{Análise da Definição dos Objetos Estratégicos e Seus Indicadores}

Na descrição do planejamento estratégico um dos objetivos citados é fazer com que a empresa júnior universitária em questão se torne a articuladora entre as empresas juniores do sul de Minas Gerais. Este objetivo mostra não só o fenômeno do polifonismo, onde a empresa júnior, objeto deste artigo, tem como foco articular as práticas organizacionais de mais empresas a fim de englobar condutas comuns; mas também a questão da hegemonia. Se a empresa júnior universitária em questão se tornasse articuladora deste monofonismo seria desencadeadora de uma pirâmide hierárquica invariavelmente presente nas relações de hegemonia.

Além disso, um dos objetivos deste bloco é o interesse em ter certificação da ISO, colocando a empresa júnior como padrão de conduta a ser seguido e, portanto, como soberania sob as outras empresas júnior, o que mostra também uma questão de polifonia com outras empresas maiores que já tem a certificação ISO e são reconhecidas por isto. 


\subsection{Análise do Desdobramento do Plano Estratégico}

Mintzberg, Ahlstrand e Lampel (2010) prevêem que toda aplicabilidade de planejamento estratégico tem como objetivo principal evitar um único dano maior, que é a perda de tempo e dinheiro, o que foi adquirido com sucesso pela empresa júnior em questão. No planejamento estratégico está descrito que com o sucesso da implantação deste plano "(...) outras empresas se inspirem neste caso, e que possam se favorecer de seus benefícios" mostrando mais uma vez a latência das características do fenômeno da hegemonia, uma vez que há implicitamente aqui o intuito de se propagar a prática organizacional da empresa júnior e se colocar suas práticas sociais como primordiais para adquirir o sucesso no planejamento estratégico.

\section{Considerações Finais}

Este artigo teve como objetivo principal analisar, sob a ótica da análise de discurso proposta por Bakhtin, as características de linguagem de um planejamento estratégico de uma empresa júnior situada no sul do estado de Minas Gerais. Os objetivos específicos foram: primeiramente, identificar quais são as características textuais e discursivas presentes no documento descritivo do planejamento estratégico da empresa júnior. Vê-se que o que se descreve e o que pretende com o planejamento estratégico são coisas distintas, ou seja, nem tudo que está explícito no texto é o que se pretende alcançar como meta clara, muito do que se pretende conquistar pela empresa júnior está encoberto nos fenômenos polifônicos e na hegemonia.

O segundo objetivo específico foi verificar características de polifonia presentes no corpus do documento que descreve o planejamento estratégico da empresa júnior, e estas características estavam presentes no atrito entre as vozes na diretoria da empresa e dos trainnes, e da própria empresa e da instituição estudantil similar que ocupa sede no mesmo departamento da empresa júnior em questão, e da empresa júnior e da Brasil Júnior.

O terceiro objetivo específico foi verificar sob o conceito de polifonia, se o planejamento estratégico em questão possui características com predominância de monofonia ou polifonia, concluindo pela análise que há predominância de polifonia. Apesar de a intenção ser monofônica, ou seja, de não apresentar as vozes de forma direta e ter impessoalidade.

O quarto objetivo específico foi avaliar quais são os caracteres de hegemonia presentes na linguagem textual do plano estratégico. Percebe-se principalmente na questão de interesse de certificação da ISO que a empresa júnior universitária tem interesse de sobrepor suas práticas sob as demais empresas júnior e se tornar padrão de conduta.

À medida que se responde estas questões, se aponta a problemática central do artigo: Quais são as especificidades textuais e discursivas utilizadas no planejamento estratégico de modo a analisar a estratégia sob a ótica da análise de discurso proposta por Bakhtin? O corpus do planejamento estratégico passa uma ideia de impessoalidade, como se não houvesse intenção de quem se fala e nem para quem se fala, não há definição de tempo nem de gênero o que aprofunda essa sensação de devaneio e caracteriza monofonia.

Por mais que o planejamento estratégico seja um documento em que os atores tenham livre possibilidade de dialogarem e expressarem opinião, há um limite imposto pela Brasil Júnior o que delimita suas conquistas. Muito do que se propõe também gera polifonia no sentido de transitar o poder de tomada de decisão (ou a ilusão dele) entre a diretoria e os colaboradores da empresa, provocando características de ideologia.

Para futuros trabalhos se sugere que há aprofundamento maior nas relações de poder e ideologia presentes no corpus do planejamento estratégico da empresa júnior pesquisada neste artigo. 


\section{BIBLIOGRAFÍA}

Ahlstrand, B., Lampel, J., \& Mintzberg, H. (2000). Safári de estratégia: um roteiro pela selva do planejamento estratégico. Bookman: Porto Alegre, 2000.

Aucoin, P., \& Peter, A. (1995). The new public management: Canada in comparative perspective. Montreal: Institute for Research on Public Policy.

Bakhtin, M. (2009). Marxismo e filosofia da linguagem. São Paulo: Hucitec, 2002. _. Estética da criação verbal, 4.

Bakhtin, M. M. (1992). Estética da criação verbal. [Tradução feita a partir do francês por Maria Emsantina Galvão G. Pereira revisão da tradução Marina] São Paulo: Livraria Martins Fontes. Ano 1997. — (Coleção Ensino Superior).

Barros, D. L. P. D. (1997). Contribuições de Bakhtin às teorias do discurso. Bakhtin, dialogismo e construção do sentido, 2, 25-36.

Barry, D., \& Elmes, M. (1997). Strategy retold: Toward a narrative view of strategic discourse. Academy of management review, 22(2), 429-452.

Bezerra, P. (2005). Polifonia. Bakhtin: conceitos-chave, 4, 191-200.

Boston, J., Martin, J., Pallot, J., \& Walsh, P. (1991). Reshaping the state: New Zealand's bureaucratic revolution. Victoria University of Wellington Print.

Coase, R. H. (1937). The nature of the firm. Economica, 4(16), 386-405.

de Souza Minayo, M. C. , Deslandes, S. F., Cruz Neto, O., Gomes, R. (2011). Pesquisa social: teoria, método e criatividade. Editora Vozes Limitada- Petropolis, RJ 1994.

Goulart, C. (2001). Letramento e polifonia: um estudo de aspectos discursivos do processo de alfabetização. Red Revista Brasileira de Educação, 18 (Set/Out/Nov/Dez 2001), pp- 5 - 21.

Graham, C. (2002). Strengthening institutional capacity in poor countries. Brookings Institution.

Holmes, M., \& Shand, D. (1995). Management reform: some practitioner perspectives on the past ten years. Governance, 8(4), 551-578.

Hood, C., \& Jackson, M. W. (1991). Administrative argument (Vol. 5). Aldershot: Dartmouth.

Jarzabkowski, P. (2005). Strategy as practice: An activity based approach. Sage.

Kuhn, T. S. (1996). The Structure of Scientific Revolutions. Chicago and London: The University of Chicago Press.

Martin, W. (1986). Recent theories of narrative. Cornell University Press.

Martins, H. F. (2001). Post liberal State reform: the emerging paradigm and the Brazilian experience. In Congresso del CLAD.

Martins, H. F. (1997). Administración pública gerencial y burocracia. La persistencia de la dicotomía entre política y administración. Reforma y Democracia, 9, 131-158.

Moore, M. H. (1995). Creating public value: Strategic management in government. Harvard university press.

Miotelio, V. (2005). Ideologia. Bakhtin: conceitos-chave. São Paulo: Contexto, 167-176.

Moretto Neto, L., Junkes, P. N., Rosauro, D. Z., \& Benko, F. (2004). Empresa Júnior: espaço de aprendizagem. Florianópolis:[sn].

Oliveira, E. M. (2003). Empreendedorismo social e empresa júnior no Brasil: o emergir de novas estratégias para formação profissional. Franca-SP: Ribeirão Gráfica e Editora.

Offe, C. (1998). The present historical transition and some basic design options for societal institutions. Unpublished, Brasilia: MARE.

PNUD (2004) Desenvolvimento humano. http://www.pnud.org.br/index.php?lay=idhp\&id=idhp\#link2.

Politt, C. (1990). Managerialism and the public services: The Anglo-American experience.

Rezende, F. D. C. (1996). Os leviatãs estão fora de lugar. Dados, 39(2), 195-210. 
Rezende, F. D. C. (2000). Administrative Reform, Permanent Failure, and the Problem of the External Support: MARE and the Reform of the State Apparatus in Brazil. Unpublished PhD thesis, Cornell University.

Rinne, J. J. (2002). Redesigning the state in Latin America: Pundits, policymakers, and organized labor in Argentina and Brazil.

Rocha, D., \& Deusdará, B. (2005). Análise de Conteúdo e Análise do Discurso: aproximações e afastamentos na (re) construção de uma trajetória. Alea: Estudos Neolatinos, 7(2), 305-322.

Rodrik, D., \& Subramanian, A. (2003). The Primacy of Institutions (and what this does and does not mean), in Finance and Development.

Schick, A. (1996). The Spirit of Reform: Managing the New Zealand State Sector in a Time of Change; a Report Prepared for the State Services Commission and the Treasury, New Zealand. State Services Commission.

Silva, F. T., Maia, M. H. B., Tavares, W., \& Joaquim, N. D. F. (2010). O Processo de Gestão do Conhecimento em Redes Interorganizacionais: Um estudo com empresas juniores de Minas Gerais. Anais... XXXIV Encontro da ANPAD, Rio de Janeiro, 25.

Stiglitz, J. (2000). What I learned at the world economic crisis. Globalization and the poor: Exploitation or equalizer, 195-204.

Vaara, E., Kleymann, B., \& Seristö, H. (2004). Strategies as discursive constructions: The case of airline alliances. Journal of Management Studies, 41(1), 1-35.

Vaara, E., Sorsa, V., \& Pälli, P. (2010). On the force potential of strategy texts: a critical discourse analysis of a strategic plan and its power effects in a city organization. Organization, 17(6), 685-702.

Whittington, R. (1996). Strategy as practice. Long range planning, 29(5), 731-735.

Williamson, J. (1990). The progress of policy reform in Latin America (No. E10 W745). Institute for International Economics, Washington, DC (EUA).

Zacchi, V. J. (2003). Discurso, poder e hegemonia: dilemas do professor de língua inglesa.

Zacchi, V. (2006). Linguagem e subjetividade em Gramsci e Bakhtin. Gragoatá, 11(20). 